\title{
PLANOS DECENAIS DE EDUCAÇÃO EM MUNICÍPIOS DO INTERIOR PAULISTA: ANÁLISE DO ACOMPANHAMENTO E MATERIALIZAÇÃO DAS METAS ESTRUTURANTES
}

https://dx.doi.org/10.5902/2318133867791

\author{
Tatiane Oliveira Santos Nascimento ${ }^{1}$ \\ Silvio Cesar Nunes Militão²
}

\begin{abstract}
Resumo
Neste texto, relata-se resultados de pesquisa que teve como objetivo analisar o processo de monitoramento e avaliação atinente à implantação dos planos municipais de educação em 16 municípios jurisdicionados a um polo interiorano da União Nacional dos Dirigentes Municipais de Educação. Metodologicamente, valeu-se de pesquisa documental, bibliográfica e estudo exploratório com base nos dados trazidos pela plataforma PNE em movimento, com indicadores das metas estruturantes do Plano Nacional de Educação para a garantia à educação básica com qualidade. Os resultados evidenciam que, nos municípios sob exame, está havendo um movimento posterior à elaboração dos subplanos para sua efetiva materialização.

Palavras-chave: planos municipais de educação; monitoramento; avaliação; materialização.
\end{abstract}

\section{DECENNIAL EDUCATION PLANS IN SÃO PAULO COUNTRYSIDE MUNICIPALITIES: ANALYSIS OF MONITORING AND MATERIALIZATION OF STRUCTURING GOALS}

\begin{abstract}
This text reports findings from a research whose aimed at analyzing the process of monitoring and assessment regarding the municipal education plans implantation in 16 municipalities within a countryside pole of the União Nacional dos Dirigentes Municipais de Educação. Methodologically, the research is a documental, bibliographic and exploratory study based on data from the PNE em movimento platform, with indicators of the National Education Plan structuring goals to ensure Basic Education with quality. Findings made evident t5hat in examined municipalities there is a movement posterior to the subplans elaboration for their effective materialization.

Key-words: municipal education plans; movement; assessment; materialization.
\end{abstract}

1 Universidade Estadual Paulista Júlio de Mesquita Filho, campus Presidente Prudente, Brasil. E-mail: tatiosn@hotmail.com.

2 Universidade Estadual Paulista Júlio de Mesquita Filho, campus Presidente Prudente, Brasil. E-mail: silvio.militao@unesp.br.

Regae: Rev. Gest. Aval. Educ. 


\section{Introdução}

m 2014, a partir da lei n. 13.005 (Brasil, 2014a), aprovou-se o Plano Nacional de Educação - PNE -, com vigência decenal, pelo qual se estabelecem diretrizes e metas.

Visando a um regime de colaboração entre os entes federados, o artigo $8^{\circ}$ prevê que a União, os Estados, o Distrito Federal e os municípios deverão elaborar ou adequar seus respectivos planos de educação em consonância com as diretrizes, metas e estratégias previstas no PNE, tarefa a ser executada no prazo de um ano a partir da publicação da lei.

Nesse processo, a dinâmica de elaboração e adequação dos denominados subplanos - os Planos Estaduais de Educação - PEEs - e os Planos Municipais de Educação - PMEs -, implicaria na ampla participação dos representantes da comunidade educacional e da sociedade civil. O propósito era que toda essa sintonia, entre as esferas de governo, instituísse o Sistema Nacional de Educação - SNE - dois anos após a publicação da lei do Plano.

Em estudo anterior (Nascimento, 2018), buscamos compreender o referido movimento entre a esfera local e nacional, analisando o processo de elaboração dos PMEs no âmbito de um polo regional da União Nacional dos Dirigentes Municipais de Educação - Undime ${ }^{-3}$, composto por 16 municípios de pequeno e médio porte do Oeste paulista. Intentamos apreender os limites $e$ as possibilidades das referidas municipalidades na elaboração de seus principais documentos locais de planejamento e política educacional.

Inicialmente, foi realizado um levantamento sobre a situação legal dos municípios quanto aos seus correspondentes PMEs, o qual mostrou que, dos 16 municípios, apenas nove haviam inserido seus respectivos planos de educação no Portal do $\mathrm{PNE}^{4}$. $\mathrm{Na}$ sequência, em posse dos textos desses nove PMEs, procedemos a leitura dos os documentos buscando identificar diferenças substanciais entre eles. Foi feita uma tabulação dos dados referentes aos conteúdos dos planos. Estabelecemos, então, um exame comparativo entre as metas e as estratégias de cada documento e, partir deste cotejamento, constatamos que apenas dois desses PMEs se distinguiam dos demais em sua redação, denotando certo grau de autonomia em sua elaboração. Os demais planos locais apresentaram textos muito próximos - em alguns casos quase que idênticos - ao plano de âmbito nacional.

Utilizando o critério de análise da redação dos PMEs, escolhemos as duas municipalidades que apresentaram considerável distinção em seus textos legais para analisar de forma mais acurada seus respectivos processos de elaboração. Para tanto, utilizamos como aporte teórico a análise mesoanálitica, com o propósito de apreender a ação organizacional dos atores sociais frente às determinações legais, adequando as normas e considerando suas especificidades. Ao final do estudo (Nascimento, 2018),

3 A escolha do campo de estudo deve-se à considerável influência que tal entidade exerce junto às secretarias municipais de educação por meio de seus avaliadores técnicos, os quais são os principais responsáveis pela articulação entre os planos municipais, estaduais e nacional frente aos trabalhos de formação e lançamento de planos sancionados na base do Sistema Integrado de Monitoramento, Execução e Controle do Ministério da Educação - Simec.

${ }^{4}$ A pesquisa foi realizada em janeiro do ano de 2017.

\begin{tabular}{l|l|l} 
Regae: Rev. Gest. Aval. Educ. & Santa Maria & v. 11
\end{tabular}

ก. 20

e67791, p. 1-15

2022 
constamos que, em ambas municipalidades, os sujeitos, por um lado, foram guiados pelas normas oficiais oriundas da esfera federal, o que denota o caráter sistêmico e de legitimidade atinente ao referido processo e, por outro e de maneira concomitantemente, também conseguiram adequar o plano às suas necessidades locais, considerando os seus respectivos diagnósticos.

Neste contexto, apresenta-se resultados parciais da pesquisa pela qual se objetivou analisar o processo de monitoramento e avaliação atinente à implantação dos PMEs em 16 municípios jurisdicionados a um polo interiorano da Undime. Tratou-se de estudo exploratório, com base nos dados trazidos pela na plataforma PNE em movimento, com indicadores das metas estruturantes do Plano para a garantia da educação básica com qualidade da mencionada região.

Entende-se por metas estruturantes para a garantia do direito a educação básica com qualidade aquelas "dizem respeito ao acesso, à universalização da alfabetização e à ampliação da escolaridade e das oportunidades educacionais (Brasil, 2014b, p. 9). Segundo o caderno de orientação Planejando a próxima década: conhecendo as 20 metas do Plano Nacional de Educação integram este grupo as metas 1 - educação infantil, meta 2 - ensino fundamental, meta 3 - ensino médio, meta 5 - alfabetização infantil, meta 6 - educação integral, meta 7 - qualidade na educação básica, meta 9 alfabetização de jovens e adultos, meta 10 - ensino de jovens e adultos integrada e meta 11 - educação profissional.

\section{O planejamento educacional no contexto histórico}

Historicamente, a educação brasileira foi marcada pela dificuldade de acesso e permanência na escola. Somente a partir do final da década de 1980, com a promulgação da Constituição Federal de 1988, o cenário educacional ganhou novos contornos.

Ainda que a recente história da educação brasileira mostre avanços significativos quanto ao planejamento no âmbito educacional, estudos apontam que a discussão mais efetiva sobre o planejamento em âmbito educacional não é tão nova, e remonta a década de 1930, especificamente em 1932. A proposta de um projeto de renovação para a educação advém do Movimento dos Pioneiros da Educação Nova, com a "tentativa de reconstrução educacional do Brasil” (Calderón; Borges, 2014, p. 103).

Consideramos que esse foi o ponto de partida para a elaboração de um anteprojeto referente à educação nacional, inserido Constituição Federal de 1934, que designa, no art. 150, a competência da União de fixar o plano nacional de educação, compreensivo do ensino de todos os graus e ramos, comuns e especializados; e coordenar e fiscalizar a sua execução. Para Calderón e Borges (2014), a influência do Manifesto dos pioneiros da educação nova sobre a tentativa de reconstrução educacional do país constituiu um marco histórico no planejamento da educação brasileira.

Neste período, o país era governado por Getúlio Vargas (1930-1945), que marcou a chamada Era Vargas com características autoritárias de centralização administrativa. A proposta desse governante se voltava ao crescimento econômico e à redução das desigualdades sociais. A fim de executar o seu plano de desenvolvimento, Vargas traçou o crescimento industrial pelo valorização do ensino de cunho profissionalizante e tecnológico. 
Embora o Movimento dos Pioneiros tenha influenciado diversas reformas no âmbito educacional do país e permitido muitas conquistas, especialmente quanto ao acesso à educação pública e gratuita, prevalecem nesse período dois modelos distintos de oferta de ensino. De um lado, um ensino direcionado à formação das elites, as quais ocupariam cargos decisórios, do outro, um ensino voltado às camadas populares, desenvolvido com poucos recursos destinados à formação básica para qualificação de mão de obra, ambas iniciativas com a finalidade de colaborar com o desenvolvimento econômico do país.

Neste contexto, fica evidente a existência de um forte dualismo na educação brasileira, ainda presente nos dias atuais, estabelecendo um campo de disputas e interesses diversos, em nossa visão um grande desafio a ser superado. É inegável a significativa contribuição dos Pioneiros na Constituição de 1934, pois esse movimento despertou o olhar para o planejamento educacional brasileiro e provocou diversas reformas nessa área, especialmente no que tange à ampliação e acesso à educação pública e gratuita.

Contudo, concordamos com Bordignon (2014) quando afirma que o que foi elaborado em 1934 "não foi um plano, mas um anteprojeto de lei disciplinando a organização e funcionamento das instituições educativas" (p. 41). E ainda, na análise de que este anteprojeto não chegou a instituir um conjunto de metas a serem implementadas com o peso de obrigatoriedade, uma vez que foi abandonado e retomado somente em 1946, fim da era de Vargas, quando os Pioneiros voltaram a atuar de forma expressiva na Constituição de 1946.

Em 1962, atendendo às determinações da Constituição de 1946 e, concomitantemente, da primeira LDB, foi elaborada a primeira versão do Plano Nacional de Educação - PNE ${ }^{5}$. Com iniciativa do Ministério da Educação e Cultura e aprovado pelo Conselho Nacional de Educação, o primeiro PNE teve vigência de apenas dois anos até que fosse instaurado o regime militar em 1964. Na percepção de Valente, Costa e Santos (2016) este plano teve "o papel de instrumento de aplicação dos recursos financeiros pelos entes federados” (p. 30).

Embora esta primeira versão do Plano tenha servido como mecanismo de interesses econômicos e que suas metas não tenham sido implementadas e concretizadas em forma de lei, "o compromisso com a universalização do ensino, por meio da articulação dos entes federados, estabeleceu-se como eixo fundamental do plano nacional, e passou a ser cada vez mais reforçado nos planos subsequentes" (Silva; Oliveira, 2016, p. 109).

$\mathrm{Na}$ década de 1990, o cenário brasileiro ganhou novos contornos legais com a aprovação da atual Constituição. No artigo 214, esta lei estabelece o Plano Nacional de Educação com os seguintes propósitos: erradicação do analfabetismo, universalização do atendimento escolar, melhoria da qualidade do ensino, formação para o trabalho, promoção humanística, científica e tecnológica do país, e ampliação dos recursos públicos para a educação (Brasil, 1988). Tais metas foram projetadas para serem cumpridas pela União no prazo de dez anos.

\footnotetext{
5 Toma-se nota que no primeiro PNE ainda chegou a estabelecer metas quantitativas e qualitativas projetadas para um período de oito anos, mas não foi elaborado em formato de um projeto de lei.

Regae: Rev. Gest. Aval. Educ. Santa Maria

v. 11

n. 20

e67791, p. 1-15 
No contexto legal, neste período, o cenário brasileiro vai se fortalecendo também com a aprovação da vigente LDB - lei n. 9.394/96 - que, no artigo 9º, incumbe a União de elaborar o Plano Nacional de Educação em colaboração com os estados, o Distrito Federal e os municípios. Com esta determinação, circulam no Congresso Nacional duas propostas de Plano: o PNE da sociedade brasileira, PL 4.155/98, e o PNE do executivo, PL 4.173/98. A discussão culminou na lei n. 10.172, de 9 de janeiro de 2001, pela qual se aprovou o segundo PNE do país, o primeiro PNE aprovado em forma de lei com vigência decenal, especificamente de 2001 a 2010, contendo 295 metas e 11 áreas contempladas.

Sobre o processo de elaboração do PNE (2001-2010), Calderón e Borges (2014) afirmam que foi permeado por uma acirrada tensão política. Nesta perspectiva, por um lado o Plano foi elaborado sob a ótica das intenções dos movimentos sociais e, por outro, pelo ângulo do executivo seguindo acordos firmados com organismos internacionais que demandavam o comprometimento administrativo das políticas educacionais do Ministério da Educação e desconsiderava demandas locais.

Ainda sobre as duas propostas enviadas ao executivo que culminaram no PNE (2001-2010), na análise de Dourado (2016) "os dois expressavam concepções e prioridades educacionais distintas, sobretudo na abrangência das políticas, em seu financiamento e gestão, bem como no diagnóstico, prioridades, diretrizes e metas" (p. 20).

Além da tensão política mencionada, a elaboração do PNE (2001-2010) enfrentou outros problemas. Um deles diz respeito aos vetos às metas orçamentárias, o que impediu o documento de ser um instrumento de ação fundamental da educação, inviabilizando o cumprimento das metas subsequentes. Outro desafio foi a falta de discernimento para priorizar o essencial, expresso na excessiva quantidade de metas, que acabou por dificultar o acompanhamento e o controle de sua implantação. Também a não regularização do regime de colaboração entre os entes federados consolidou uma cultura avessa ao planejamento, movida pelas pressões imediatas.

Saviani (2014, p. 96), ao avaliar a vigência do PNE (2001-2010), assinala que o plano trouxe "vários avanços como a ampliação da cobertura educacional" (p. 96) e expandiu as vagas nas escolas de educação infantil, no ensino fundamental e médio, além de abrir espaço para o nível superior. O autor também aponta mudanças positivas na vigência do segundo PNE no âmbito do financiamento, destacando a substituição do Fundo de Manutenção e Desenvolvimento do Ensino Fundamental e de Valorização do Magistério - Fundef - pelo Fundo de Manutenção e Desenvolvimento da Educação Básica e de Valorização dos Profissionais da Educação - Fundeb. Tal mudança estendeu a ação do fundo para toda a educação básica.

Ainda de acordo com Saviani (2014), a instituição do Plano de Desenvolvimento da Educação Básica - PDE - abriu portas para a participação da União no desenvolvimento da educação básica e para a criação do Índice de Desenvolvimento da Educação Básica Ideb -, aprimorando os mecanismos de avaliação.

Conforme é possível observar nas análises dos autores referenciados, a configuração do PNE (2001-2010) dificultou a priorização do essencial, comprometendo de vez a sua materialização6.

\footnotetext{
6 Num estudo realizado a pedido do MEC, no último ano de vigência do PNE, demonstra que apenas $33 \%$ das metas do PNE (2001-2010) foram atingidas.

Regae: Rev. Gest. Aval. Educ. Santa Maria v. 11

n. 20

e67791, p. 1-15

2022
} 
No Relatório do Fórum Nacional de Educação, ao analisar o planejamento educacional do Brasil, em especial o PNE (2001-2010), Bordignon et al (2011) apontam que "planos na área de educação pouco pautaram a ação dos governos que os elaboraram" (p. 29). Para o fato, os autores indicam duas hipóteses ao abandono parcial ou total dos planos: uma cultura e outra política. Sobre a primeira hipótese, Bordignon et al (2011) situa "na raiz histórico-cultural do modo de governar no Brasil" (p. 29), pois os governantes priorizam a sua vontade e a sua visão de mundo não dando atenção às necessidades da sociedade. Já na dimensão política, reflete que atribuiu além das turbulências institucionais também a frequente rotatividade dos ministros da educação para esse período ${ }^{7}$.

Diante do exposto, concluímos que a implantação parcial do PNE (2001-2010) estava relacionada aos vetos financeiros e ao desinteresse político do governo no período de vigência do Plano, e que também os governos posteriores demonstraram pouco interesse em efetivá-lo. De acordo com Saviani (2014, p. 95), um estudo realizado a pedido do MEC apontou que apenas $33 \%$ das metas do PNE foram atingidas.

Foi nesse contexto que, com o intuito de romper com a fragmentação dos objetivos e a falta de foco presentes no Plano anterior, aprovou-se a lei n. 13.005, de 25 de junho de 2014, que instituiu Plano Nacional de Educação (2014-2024), traduzido em 20 metas e 170 estratégias.

\section{As metas estruturantes do atual PNE expressas em âmbito municipal}

Em 2010 aconteceu a Conferência Nacional de Educação - Conae - e, posteriormente, em 2014, a aprovação da lei n. 13.005. no art. $8^{\circ}$ foi estabelecido que

os Estados, o Distrito Federal e os Municípios deverão elaborar seus correspondentes planos de educação, ou adequar os planos já aprovados em lei, em consonância com as diretrizes, metas e estratégias previstas neste PNE, no prazo de 1 (um) ano contado da publicação desta Lei. (Brasil, 2014a)

Desde então, iniciou-se um movimento acelerado envolvendo uma ação articulada entre a União e as demais instâncias federadas para a concretização dos planos infranacionais. Com o intuito de apoiar as instâncias federadas do governo no desafio de articular os subplanos de educação ao PNE (2014-2024), a Secretaria de Articulação com os Sistemas de Ensino - Sase - elaborou o portal 'PNE em Movimento'. Neste sítio público é possível ter acesso aos textos dos PEEs e dos PMEs, como também acompanhar a situação educacional de cada ente federado.

Pelo acesso a este portal, verificamos a quase universalização da situação dos PEEs elaborados, encontrando-se em déficit apenas o Estado do Rio de Janeiro que, passados sete anos de vigência do PNE, ainda não converteu seu correspondente plano

\footnotetext{
7 "No período de 70 anos - da criação do Ministério dos Negócios da Educação e Saúde Pública pelo Presidente Vargas em novembro de 1930, até a aprovação do PNE/2001 em janeiro de 2001 - foram 19 presidentes da República, incluindo dois presidentes da Câmara como interinos, e 42 ministros da educação, sem contar os interinos. Isso dá uma média de 20 meses de permanência no cargo para cada Ministro" (Bordignon et al, 2011, p. 29).

Regae: Rev. Gest. Aval. Educ. $\quad$ Santa Maria

v. 11

ก. 20

e67791, p. 1-15

2022
} 
em norma jurídica ${ }^{8}$. Neste mesmo espaço digital verificamos que dos 5.570 municípios brasileiros, 5.568 deles já aprovaram seus respectivos PMEs. Ao que consta, os dois municípios faltantes, laras e Ribeirão Preto, ambos do Estado de São Paulo, enviaram o projeto de lei para o legislativo, mas ainda não tiveram seus planos aprovados ${ }^{9}$.

Após a aprovação do Plano, assistimos uma nova dinâmica encenada no contexto do planejamento educacional, entre elas a elaboração dos subplanos decenais de educação das esferas federadas. A lei do PNE prevê, no artigo 5ํㅜ que a execução do Plano e o cumprimento de suas metas serão objeto de monitoramento contínuo e de avaliações periódicas. Diante de tal determinação, devemos atentar sobre a relevância dessa ação, tendo em vista que sua sistematização dará vida e movimento ao texto político, e também às diretrizes, metas e estratégias pensadas e projetadas a proporcionar avanços para a educação do país.

Tradicionalmente, poucas vezes uma política de Estado designa articulação entre as instâncias federadas para o seu monitoramento. Bordignon (2014) definiu o plano como documento formal que consolida as decisões definidas no planejamento. Este autor entende o planejamento como uma ação que começa antes e continua depois do plano: "O planejamento constitui dos processos decisórios nas fases de elaboração do plano e de sua implantação, ou seja: se constitui em processo contínuo de tomada de decisões", (p. 33).

No que tange à implantação, Bordignon (2014) considera como alguns requisitos para se jogar o jogo: a não improvisação, pois a execução do plano exige uma ação contínua das estratégias planejadas; o acompanhamento permanente do efeito das estratégias no alcance das metas; a avaliação periódica dos dados do acompanhamento; e, por fim, o replanejamento capaz de sintonizar o plano ao contexto local. Este mesmo autor evidencia que o acompanhamento e a avaliação "tem a função de oferecer subsídios para o processo de correções de rumo (replanejamento)" (p. 37).

Como forma de apoiar os municípios no acompanhamento de seus planos, o MEC, por meio da Sase, disponibilizou o Caderno de orientação para o monitoramento $e$ avaliação dos PMEs (Brasil, 2016, p.7). Este material recomenda que a função de monitorar e avaliar os PMEs seja desempenhada por comissões e equipes técnicas determinadas por ato legal, como os Conselhos Municipais de Educação - CME -, os Fóruns Municipais de Educação - FME -, as secretarias municipais de educação, a comissão do Poder Legislativo, dentre outras.

No caso de o município não ter alguma dessas instâncias, a sugestão do documento é de que a secretaria de educação considere os integrantes da comissão coordenadora que participou do processo de adequação ou elaboração do plano vigente, relevando o acúmulo de conhecimentos e articulações institucionais já estabelecidas. O material também solicita que a secretaria municipal de educação constitua uma equipe técnica

\footnotetext{
8 Sobre o PEE do estado do Rio de Janeiro lembra-se que durante a permanência do PNE anterior (Lei no 10172, de 09 de janeiro de 2001), este estado teve seu plano aprovado pela Lei no 5597 , em 18 de dezembro de 2009, para o período de 10 anos (2009-2018). Observa-se que o estado demorou 8 anos, após a aprovação do plano anterior para elaborar seu respectivo plano, e o então elaborado adentrou na permanência do PNE atual em quatro anos, mas no momento do estudo o documento já se encontra desatualizado.

9 Dados consultados em 30 de junho de 2021. 
para sistematizar os dados e informações referentes ao plano, embora essa orientação "não se trata de instância obrigatória na consecução das ações de monitoramento e avaliação"(Brasil, 2016, p. 6).

Este material preconiza que a função de monitorar seja uma ação contínua de observação, uma vez publicitadas as informações a respeito do avanço que vai sendo feito para materializar as metas. Quanto à avaliação, propõe que seja um ato periódico de quantificar os resultados até então alcançados, as ações em andamento e as não realizadas, a fim de orientar as decisões e os possíveis planejamentos.

Com o propósito de delinear o estudo sobre os PMEs dos 16 municípios vinculados à região polo da Undime, realizamos uma leitura sobre a dinâmica da materialização dos planos locais embasada nos documentos legais. Para isso, buscamos como base de dados decretos, portarias ou leis que formalizassem legalmente a instância responsável pelo acompanhamento desses planos. A pesquisa foi realizada nos sites das prefeituras e câmaras municipais, como também por contatos por e-mails e telefonemas, em busca desses documentos normativos produzidos pelos municípios. O resultado da busca empreendida segue apresentado sinteticamente no quadro 1:

Quadro 1 -

Situação dos municípios sobre as instâncias sobre o acompanhamento dos PMEs.

\begin{tabular}{|l|c|}
\hline \multicolumn{1}{|c|}{ Situação } & Quantidade de municípios \\
\hline Municípios que têm comissão específica & 3 \\
\hline Municípios que têm o CME como órgão responsável & 2 \\
\hline Municípios que têm o FME como órgão responsável & 4 \\
\hline $\begin{array}{l}\text { Municípios que não apresentaram nenhum órgão } \\
\text { responsável pelo acompanhamento }\end{array}$ & 7 \\
\hline
\end{tabular}

Fonte: autores (2021).

O quadro 1 permite compreender que existem instâncias municipais em exercício contínuo de aproximação da gestão municipal às aspirações da comunidade local que tornam o processo de acompanhamento dos subplanos um trabalho coletivo e democrático. Todavia, o referido quadro também mostra, preocupantemente, o número expressivo de municípios (7 ou 43,75\%) que não apresentam nenhum colegiado formalizado para o acompanhamento de seus respectivos planos locais através de comissões.

Embora esse movimento seja essencial para a implantação das políticas públicas, procuramos compreender se essa expressão implica, de fato, no acompanhamento dos PMEs. Para isso, exploramos novamente a plataforma pública do PNE em Movimento, com o propósito de trazer o exame do andamento de seis ${ }^{10}$ metas do PNE (2014-2024)

10 Embora o caderno Planejando a próxima década: conhecendo as 20 metas do plano nacional de educação" (Brasil, 2014b), nomeei nove metas estruturantes para a garantia da educação básica, mas este estudo concentrou-se em apresentar apenas seis metas que estão diretamente ligadas as demandas da educação municipal.

Regae: Rev. Gest. Aval. Educ. Santa Maria

v. 11

ก. 20

e67791, p. 1-15

2022 
consideradas como metas estruturantes para a garantia da educação básica de qualidade segundo o documento Planejando a próxima década: conhecendo as 20 metas do plano nacional de educação" (Brasil, 2014b).

Ancorados no objetivo deste trabalho, propomo-nos analisar tão somente as metas estruturantes que são de competência legal e responsabilidade direta da esfera municipal, que são a meta referente a educação infantil (meta 1), ensino fundamental (meta 2), alfabetização infantil (meta 5), ensino infantil (meta 6), qualidade da educação básica (meta 7) e alfabetização de jovens e adultos (meta 9).

Tomamos como parâmetro o Relatório linha de base 2018 (Brasil, 2018), atendo-se especificamente às 16 municipalidades contempladas neste estudo. Assim, verificamos que todas as municipalidades se comunicam com o portal do MEC, alimentando dados sobre a educação municipal e demonstrando que o processo de monitoramento e avaliação das metas de seus respectivos planos está em curso.

Vele retomar que o grupo das nove metas estruturantes para a garantia da educação básica é uma seleção do documento oficial (Brasil, 2014b), mas como o foco deste estudo é a esfera municipal, propomo-nos analisar tão somente as metas estruturantes que são de competência legal e responsabilidade direta da esfera municipal, a saber refere-se a educação infantil (meta 1), ensino fundamental (meta 2), alfabetização infantil (meta 5), ensino infantil (meta 6), qualidade da educação básica (meta 7) e alfabetização de jovens e adultos (meta 9).

Com acesso aos dados, atentamos que para cada meta há distintos indicadores que demonstram, percentualmente, a meta prevista e a situação atual da nacional, da região, do estado e do município. Dessa forma, selecionamos a região Sudeste, o Estado de São Paulo e os 16 municípios contemplados neste estudo ${ }^{11}$. Tabulamos os dados quantitativos recolhidos da plataforma e, na sequência, fizemos o tratamento matemático desses dados, calculando as médias nacional, regional, estadual e das dezesseis municipalidades. Encontramos entre os indicadores de cada meta um fator de normalização que aproxima as metas previstas de cada indicador para uma mesma meta em percentual, de forma que esse coeficiente encontrado expresse o vigente alcance das metas estruturantes do Plano no âmbito nacional, da região sudeste, do estado de São Paulo e das 16 municipalidades do interior paulista. Essas informações estão sistematizadas nos gráficos seguintes.

11 O intuito deste artigo não é denunciar a aferição das metas na região estudada, desta forma preferiu-se manter o anonimato, tendo em vista que nada influenciará nos resultados e no objetivo proposto.

Regae: Rev. Gest. Aval. Educ. Santa Maria v. 11 n. 20 e67791, p. 1-15 2022 
Gráfico 1 -

Média dos indicadores das metas estruturantes.

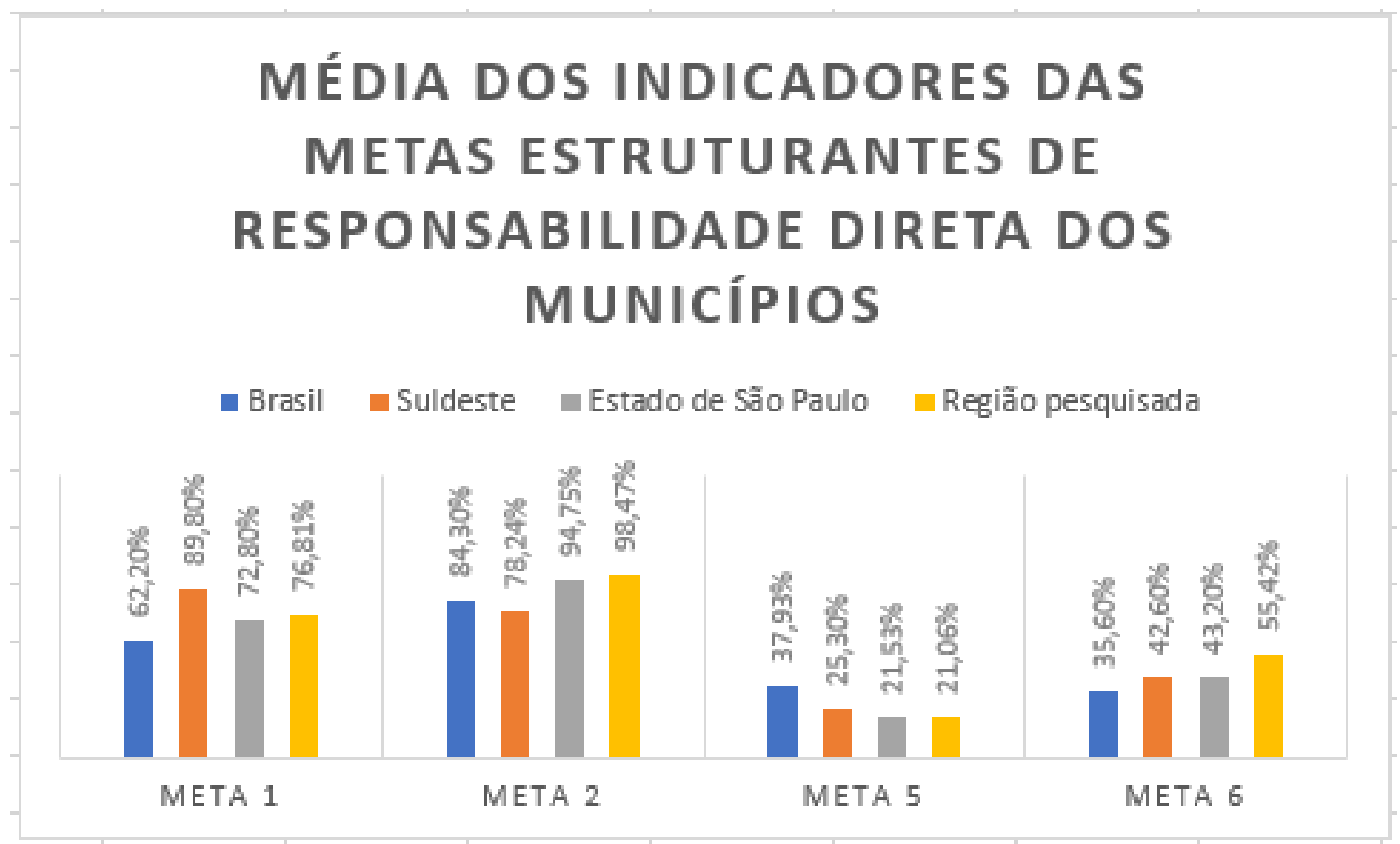

Fonte: autores.

Considerando o movimento nacional em curso para que as metas do PNE se concretizem, o gráfico permite uma compreensão sobre a Meta 1 que foca em universalizar, até 2016, a educação infantil na pré-escola para as crianças de 4 a 5 anos de idade e ampliar a oferta de educação infantil em creches, propondo a atender $50 \%$ das crianças até três anos de vigência do Plano (Brasil, 2014a). Pelo gráfico 1, destacamos os avanços na cobertura em relação à educação infantil para o Sudeste, o Estado de São Paulo e a região pesquisada, pois ultrapassaram a média nacional expressivamente. Quanto à média nacional, a previsão é que atinja os $100 \%$, no entanto o cenário demonstra um fator preocupante em relação à universalização da educação infantil no Brasil.

A Meta 2 objetiva universalizar o ensino fundamental de 9 anos para toda a população de 6 a 14 anos e garantir que pelo menos $95 \%$ dos alunos concluam essa etapa na idade recomendada, até 2024 (Brasil, 2024a). A leitura do gráfico expressa médias satisfatórias dos indicadores para as quatro instâncias comparadas, tendo em vista que a nossa região já alcançou a meta estipulada e o Estado de São Paulo também está bem próximo de atingir a previsão mínima.

A meta 5 preconiza alfabetizar todas as crianças, no máximo até o final do $3^{\circ}$ ano do ensino fundamental. $\mathrm{O}$ gráfico 1 demonstra que em relação à proficiência da leitura as instâncias contempladas neste artigo ainda se encontram distante da previsão dos indicadores; ressaltamos aqui o fato de a média nacional superar expressivamente a região sudeste, o estado de São Paulo e os municípios do interior paulista. 
A meta 6 do PNE visa a ampliar a oferta da educação em tempo integral. A análise demonstra que, embora as médias encontram-se próximas no âmbito das quatro esferas investigadas neste estudo, o desempenho da região pesquisada para a implantação dessa meta sobressai satisfatoriamente em nível nacional, da região Sudeste e do Estado de São Paulo.

Sobre a meta 7 , que propõe fomentar a qualidade da educação básica em todas as etapas e modalidades, com melhoria do fluxo escolar e da aprendizagem de modo a atingir a média nacional para o Ideb - 6,0 nos anos iniciais do ensino fundamental; 5,5 nos anos finais do ensino fundamental; 5,2 no ensino médio - vemos que marca avanços expressivos quanto à previsão. Porém, ressaltamos a discrepância entre os indicadores, pois matematicamente não se encontra um fator normalizante para calcular a média entre eles. Dessa maneira, observamos que na esfera federal, estadual e municipal os indicadores 7A - Média do Ideb nos anos iniciais do ensino fundamental - e 7B - Média do Ideb nos anos finais do ensino fundamental - estão muito próximos da meta prevista, representando por vez a universalização da meta. Quanto ao indicador 7C - média do Ideb no ensino médio - a plataforma não apresenta dados municipais, mas no âmbito nacional a meta atual $(3,7 \%)$ ultrapassou a metade da meta prevista $(5,2 \%)$. Salientamos que, como matematicamente é impossível normalizar os dados para um mesmo coeficiente, optamos por não expressar essa meta por meio de gráfico.

A meta 9 do PNE (2014-2024), referente à alfabetização de jovens e adultos, tem dois objetivos: elevar a taxa de alfabetização da população com 15 anos ou mais, alcançando $93,5 \%$ até 2015 e garantindo a erradicação do analfabetismo absoluto até o final da vigência do Plano, e reduzir em 50\% a taxa de analfabetismo funcional até 2024. Para acompanhamento, atribui-se dois indicadores: 9A - taxa de alfabetização da população de 15 anos ou mais de idade - com previsão de alcance de 93,50\% - e o indicador 9B - taxa de analfabetismo funcional da população de 15 anos ou mais de idade - com meta prevista de 15,30\% (Brasil, 2014a). Considerando a discrepância entre a previsão das metas, também não se encontra um fator de normalização que descreva a média entre esses indicadores. No entanto, optamos por apresentar esses dados separadamente, conforme mostra o gráfico 2. 
Gráfico 2 -

Descrição das esferas federadas do Indicador $9 \mathrm{~A}$.

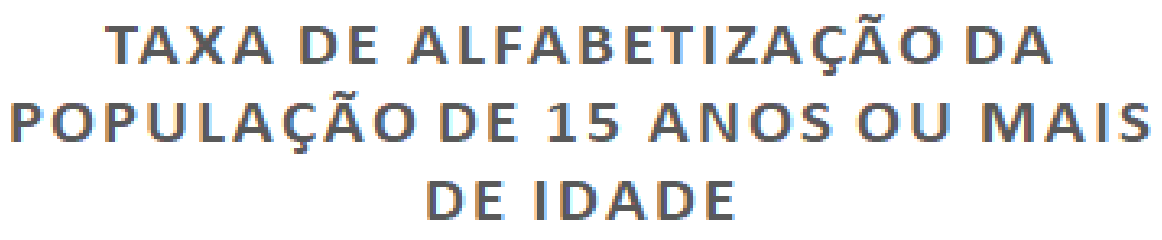

- Média Prevista = Brasil a Suldeste anstado de São paulo a Região Pesquisada
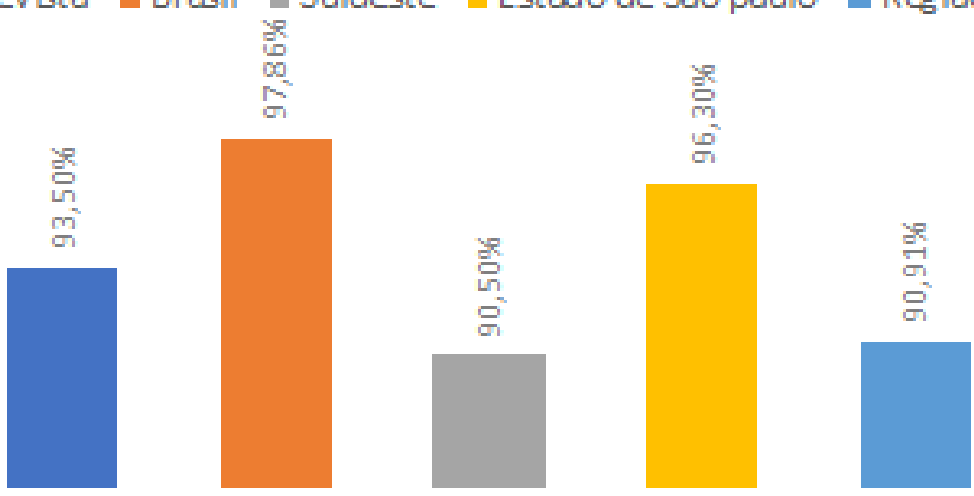

Fonte: autores.

Perante o exposto, observamos que a meta prevista, 93,5\%, para o indicador $9 \mathrm{~A}$ Taxa de alfabetização da população de 15 anos ou mais de idade - foi ultrapassada pelo estado de São Paulo. Ressalta-se que os índices nacionais, regionais da região municipal pesquisada muito se aproximam da previsão e não apresentam grandes desigualdades, uma vez que que a média de todas ultrapassa os $90 \%$.

Gráfico 3 -

Descrição das esferas federadas do Indicador 9B.

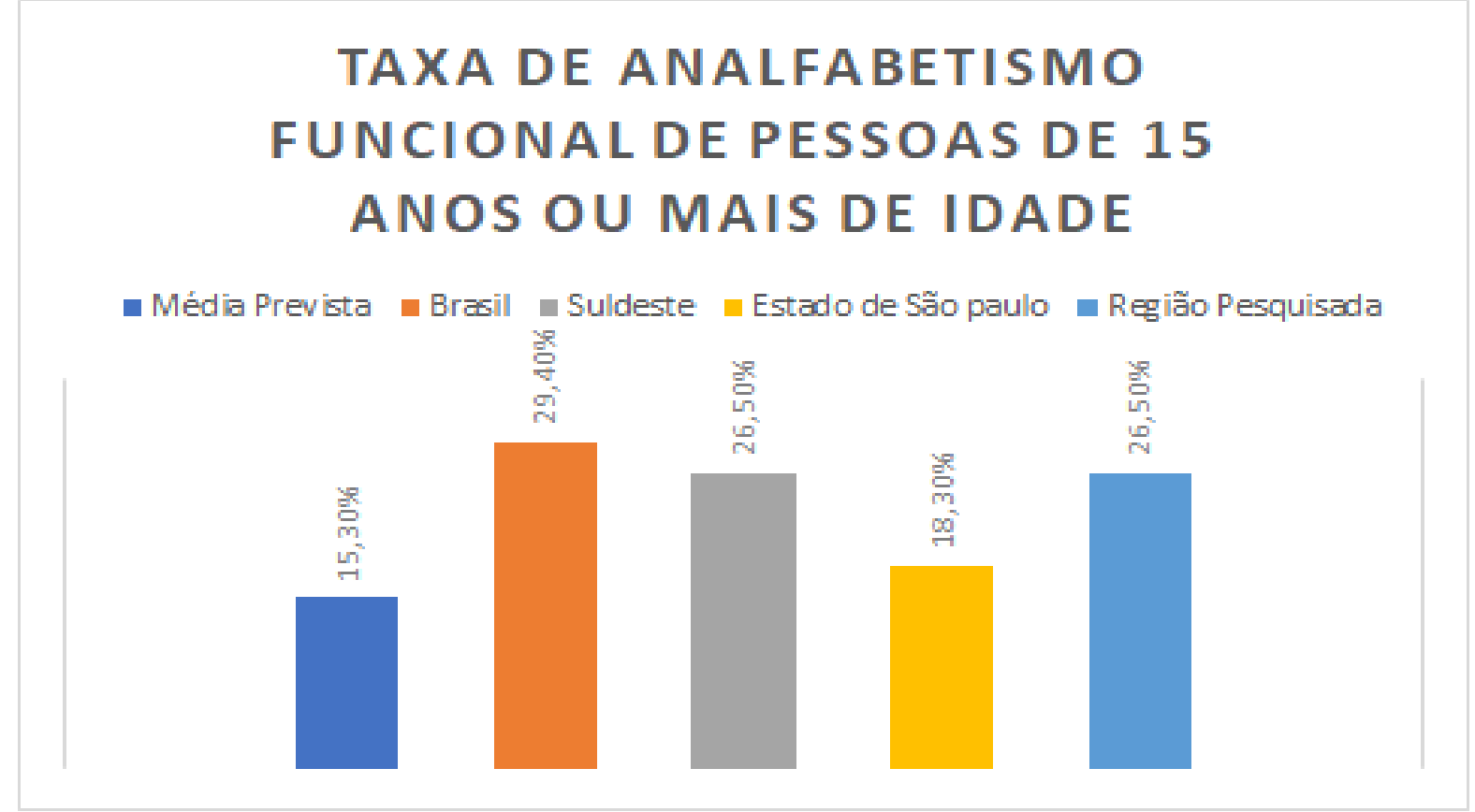

Fonte: autores. 
Conforme apresentado no gráfico 3 - acerca do Indicador 9B taxa de analfabetismo funcional de pessoas de 15 anos ou mais de idade - o objetivo pretendido é de 15,30\%, ou seja, é inverso ao indicador $9 \mathrm{~A}$. Este indicador provisiona baixo percentual ao número de analfabetismo. No que tange ao exposto, observa-se que no cenário brasileiro, considerando-se a região Sudeste, o Estado de São Paulo e os dezesseis municípios contemplados neste estudo, ainda há considerável expressividade na taxa de analfabetos funcionais, estando as médias aritméticas bem distantes da meta prevista.

O processo de análise obtida por meio do recolhimento dos dados da plataforma 'PNE em movimento', demonstra que o andamento da implantação das metas estruturantes relacionadas às incumbências educacionais diretas das esferas municipais dá mostras significativas dos caminhos que chagarão ao final da vigência do Plano, tendo em vista que falta menos da metade do tempo inicialmente previsto para que se consolidem as ações planejadas.

\section{Considerações finais}

O levantamento empreendido em relação à existência de instâncias de acompanhamento do planos municipais de educação revelou, por um lado, importante e imprescindível movimentação local voltada à institucionalização de tal acompanhamento na maioria das municipalidades estudadas. Mas por outro lado, constatou-se também que em parte expressiva dos municípios sob exame ainda não há qualquer composição coletiva ou formalizada destinada a referida finalidade.

Embora os resultados não expressem fielmente as ações concretas desenvolvidas pelas esferas municipais para a concretude das metas estruturantes que estão diretamente relacionadas às suas incumbências educacionais, observamos que nestas esferas está havendo um movimento posterior à elaboração dos subplanos para sua efetiva materialização, o que se comprovou pelo pleno alcance das metas 1- educação infantil, meta 2- ensino fundamental e meta 6 - ensino integral e pela proximidade de atingimento da meta 9 , que se refere a alfabetização de jovens e adultos, considerando a análise feita separadamente de seus indicadores. Somente a meta 5 , que se referente a alfabetização infantil, encontra-se distante de atingir o projetado dentro da vigência decenal.

O estudo também demonstrou que a cooperação entre as instâncias de governo não acontece em sintonia, sobretudo ao observarmos a assimetria no alcance ou não das metas nas diferentes instâncias estudadas. Há de se levar em conta, neste caso, as desigualdades de recursos técnicos e financeiros existentes entre a União, Estados e municípios.

Por fim, cumpre ressaltar que no tocante ao processo de monitoramento e avaliação dos PMEs, não existe fórmula pronta e universal para tal realização, mas há que se registar a necessidade de que esse processo seja contínuo durante a vigência do plano, assim como aconteça de forma articulada entre os responsáveis pelo processo.

\section{Referências}

BORDIGNON, Genuíno et al. O planejamento educacional no Brasil. Brasília: Fórum Nacional de Educação, 2011. 
BORDIGNON, Genuíno. Caminhar da educação brasileira: muitos planos, pouco planejamento. In: DONALDO, Bello de Souza; MARTINS, Angela Maria (org.). Planos de educação no Brasil: planejamento, políticas, práticas. São Paulo: Loyola, 2014, p. 29-53.

BRASIL. Cadernos de orientações para monitoramento e avaliação dos planos municipais de educação. Brasília: MEC/Sase, 2016.

BRASIL. Constituição da República Federativa do Brasil de 1934. Brasília: Presidência da República, 1935.

BRASIL. Constituição da República Federativa do Brasil de 1988. Brasília: Senado, 2020a.

BRASIL. Lei n. 10.172, de 09 de janeiro de 2001: aprova o Plano Nacional de Educação. Brasília: DOU, 2001, p. 1.

BRASIL. Lei n. 13.005, de 24 de Junho de 2014: aprova o Plano Nacional de EducaçãoPNE. Brasília: DOU, 2014a, p. 1, Edição Extra.

BRASIL. Lei n. 9394, 20 de dezembro de 1996: aprova a Lei de Diretrizes e Bases da Educação Nacional. Brasília: Senado Federal, 1996.

BRASIL. Planejando a próxima década: conhecendo as 20 metas do plano nacional de educação. Brasília: MEC/Sase, 2014b.

BRASIL. Relatório do $2^{\circ}$ ciclo de monitoramento das metas do plano nacional de educação. Brasília: Inep, 2018.

CABRAL NETO, Antônio; CASTRO, Alda Maria Duarte Araujo; GARCIA, Luciane Terra dos Santos. Plano municipal de educação: elaboração, acompanhamento e avaliação no contexto do PAR. RBPAE, Porto Alegre, v. 32, n. 1, 2016, p. 47-67.

CALDERÓN, Adolfo Ignacio; BORGES, Regilson Maciel. Construção dos planos nacionais de educação no Brasil: grupos de articulação de interesses em ação. In: DONALDO, Bello de Souza; MARTINS, Angela Maria (org.). Planos de educação no Brasil: planejamento, políticas, práticas. São Paulo: Loyola, 2014, p. 99-119.

DOURADO, Luiz Fernando. Avaliação do plano nacional de educação 2001-2009: questões estruturais e conjecturas de uma política. Educação e Sociedade, Campinas, v. 31, n. 112, 2010, p. 677-705.

DOURADO, Luiz Fernando. Plano nacional de educação: o epicentro das políticas de estado para a educação brasileira. Goiânia: Anpae, 2017.

GUMIEIRO, Angela Hess; MILITÃO, Silvio Cesar Nunes. As ações para monitorar e avaliar o plano estadual de educação de Mato Grosso do Sul (2014-2024). Regae: Rev. Gest. Aval. Educ. Santa Maria, v. 10, n. 19, 2021, p. 1-13.

LÜDKE, Menga; ANDRÉ, Marli. Pesquisa em educação: abordagens qualitativas. Rio de Janeiro: EPU, 2018.

MILITÃO, Silvio Cesar Nunes. Financiamento da educação básica no novo plano nacional de educação: avanços, impasses e perspectivas. Revista Contrapontos-Eletrônica, Itajaí, v. 16, n. 3, 2016, p. 361-382.

MILITÃO, Silvio Cesar Nunes; ARANDA, Maria Alice de Miranda. Dos primórdios à (quase) universalização dos planos de educação no Brasil: avanços e desafios no cenário contemporâneo. Textura, Canoas, v. 21 n. 48, 2019, p. 54-71.

MILITÃO, Silvio Cesar Nunes; ARANDA, Maria Alice de Miranda. Monitoramento e avaliação dos planos decenais de educação: uma análise conceitual-legal. Revista Contrapontos, Itajaí, v. 20, n. 1, 2020, p. 53-70. 
NASCIMENTO, Tatiane Oliveira Santos. O plano nacional de educação e os desafios para a elaboração dos planos municipais de educação. 2018. Presidente Prudente: Universidade do Oeste Paulista, 2018. 111f. Dissertação (Mestrado em Educação) Programa de Pós-Graduação em Educação, Universidade do Oeste Paulista.

PINTO, José. Marcelino de Rezende. Prefácio. In: MILITÃO, Andréia. Nunes; PERBONI, Fábio (orgs.). Plano nacional de educação: diversos olhares. Curitiba: CRV, 2017, p. 1718.

POLETTI, Ronaldo. Coleção constituições brasileiras. Brasília: Senado Federal, 2012.

SAVIANI, Dermeval. Sistema nacional de educação e plano nacional de educação: significado, controvérsias e perspectivas. Campinas: Autores Associados, 2014.

SAVIANI, Dermeval. Sistemas de ensino e planos de educação: o âmbito dos municípios. Educação \& Sociedade, Campinas, v. 20, n. 69, 1999, p. 119-136.

SILVA, Leandro Vitoriano; OLIVEIRA, Maria Eliza Nogueira. O Plano Municipal de Educação: da autonomia construída à autonomia decretada. Revista Teias, Rio de Janeiro, v. 17, n. 47, 2016, p. 107-113.

VALENTE, Lucia de Fátima; COSTA, Maria Simone Pereira Ferraz Moreira Costa; SANTOS, Fernando Henrique dos. Nas trilhas do planejamento educacional e seus contornos nas políticas de educação no Brasil. RBPAE, Porto Alegre, v. 32, n. 1, 2016, p. $25-45$.

Tatiane Oliveira Santos Nascimento é estudante no curso de Doutorado em Educação da Universidade Estadual Paulista Júlio de Mesquita Filho, campus de Presidente Prudente.

Orcid: https://orcid.org/0000-0001-5724-0732.

Endereço: Rua Milton Valeriano da Silva, 311 - 19026-695- Presidente Prudente SP - Brasil.

E-mail: tatiosn@hotmail.com.

Silvio Cesar Nunes Militão é professor na Universidade Estadual Júlio Mesquita Filho, campus de Presidente Prudente.

Orcid: https://orcid.org/0000-0003-2094-1193.

Endereço: Rua Roberto Simonsen, 305 - 19060-900 - Presidente Prudente - SP Brasil.

E-mail: silvio.militao@unesp.br.

Critérios de autoria: os autores, coletivamente, conceberam a ideia. Realizaram estudos referenciais, a concepção, materialização, análise e interpretação dos resultados, assim como, contribuíram para a versão final do texto em tela.

Recebido em 23 de setembro de 2021.

Aceito em 6 de janeiro de 2022.

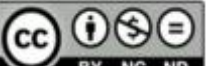

